\title{
First report of sunflower leaf spot caused by Curvularia lunata in China
}

\author{
Mandela Elorm Addrah ${ }^{1}$ (D - Bixian Shi ${ }^{2} \cdot$ Haoyu $\mathrm{Li}^{1} \cdot$ Yan Ningning ${ }^{1} \cdot$ Jian Zhang ${ }^{1} \cdot$ Jun Zhao ${ }^{1}$
}

Received: 26 January 2021 / Accepted: 5 August 2021 / Published online: 16 August 2021

(c) Società Italiana di Patologia Vegetale (S.I.Pa.V.) 2021

Keywords Curvularia lunata $\cdot$ Sunflower leaf spot $\cdot$ Identification $\cdot$ Morphology $\cdot$ Phylogenetic tree

In January 2019, sunflower (Helianthus annuus L.) fields in Hainan province sunflower off-season propagation base in Jiusuo and Haitang county, China had diseased leaves exhibiting small yellow lesions with brown borders. The average disease incidence was $10 \%$. Diseased samples were surface sterilized in $70 \%$ alcohol for $1 \mathrm{~min}$, rinsed with distilled water then cultured on Potato Dextrose Agar (PDA) medium. The actively growing colonies surrounding the diseased tissues were subcultured twice on PDA media to generate a pure culture, LD4-1. The colony morphology was gray and fluffy. Conidiophores were $120 \mu \mathrm{m}$ long and sparingly branched. Conidia were $32 \mu \mathrm{m} \times 9.8 \mu \mathrm{m}$, erect and oblong shaped with three septate cells. The DNA of LD4-1 was extracted and the internal transcribed spacer region of the DNA was amplified using ITS1/ ITS4 and GDF/ GDR primers (GAPDH genetic region). The sequenced amplicons were queried in NCBI-BLAST with a $100 \%$ similarity to Curvularia lunata (Wakker) Boedjin (Macri and Lenna 1974) isolate E16 with accession number MH183194.1. The DNA sequence of LD4-1 was deposited in GenBank corresponding with the accession numbers MN587964 (ITS) and MZ425924 (GAPDH). The sequence was aligned with verified $C$. lunata data recovered from the CBS database to construct phylogenetic tree which showed a $99 \%$ relationship. The pathogenicity of LD4-1 was carried out on 18 detached LD5009 sunflower leaves (12:6) inoculated with $1 \mathrm{~cm}$ plugs of LD4-1 and non-inoculated PDA plugs, respectively. The leaves were placed on moist filter papers

Mandela Elorm Addrah, Bixian Shi are contributed equally to this work

Jun Zhao

zhaojun@imau.edu.cn

1 College of Horticulture and Plant Protection, Inner Mongolia Agricultural University, Hohhot, China

2 Industrial Crops Institute of Xinjiang Academy of Agricultural Sciences, Urumqi, Xinjiang, China in covered plastic containers inside the growth chamber. Water soaked lesions appeared around LD4-1 plugs which gradually turned dark brown but not the control leaves. The same fungus was re-isolated from the lesions and the colony morphology were same as LD4-1. C. lunata is a facultative pathogen known to affect mostly monocotyledonous hosts. In China, C. lunata has been reported to cause leaf spot not only on maize (Dai et al. 1995), but also sorghum (Xu et al. 2018). To our knowledge, this is the first report of $C$. lunata causing sunflower leaf spot in China.

Supplementary Information The online version contains supplementary material available at https://doi.org/10.1007/s42161-021-00929-8.

Acknowledgements This research was funded by China Ministry of Agriculture, China Agricultural Research System (CARS-14), the Inner Mongolia Science and Technology Application Project (201803048) and Inner Mongolia Key Fund for Science and Technology.

\section{Declarations}

Conflicts of interest The authors declare no conflict of interest. The funders had no role in the design of the study; in the collection, analyses, or interpretation of data; in the writing of the manuscript, or in the decision to publish the results".

\section{References}

Dai FC, Gao WD, Wu RJ, Jin XH (1995) A noticeable corn disease: Curvularia leaf spot. ACTA Phytopathol Sin 25:330

Macri F, Lenna PJ (1974) Leaf corn blight incited by Curvularia lunata (Wakk.) Beod. J Plant Pathol 10:27-35

Xu G, Zheng F, Ma R, Zheng FQ, Zheng L, Ding XF, Xie CP (2018) First report of Curvularia lunata causing leaf spot of Pennisetum hydridum in China. Plt Dis 102(11):2372

Publisher's Note Springer Nature remains neutral with regard to jurisdictional claims in published maps and institutional affiliations. 